\title{
Discordance in Grading Methods of Aortic Stenosis by Pre-Cardiopulmonary Bypass Transesophageal Echocardiography
}

\author{
George Whitener, MD,* Jeff McKenzie, MD,* Igor Akushevich, PhD, † William D. White, MPH, \\ Ishwori B. Dhakal, MS,* Alina Nicoara, MD, FASE,* and Madhav Swaminathan, MD, FASE, FAHA*
}

\begin{abstract}
BACKGROUND: Current guidelines define severe aortic valve stenosis (AS) as an aortic valve area $(A V A) \leq 1.0 \mathrm{~cm}^{2}$ by the continuity equation and mean gradient $\left(\Delta P_{m}\right) \geq 40 \mathrm{~mm} \mathrm{Hg}$. However, these measurements can be discordant when classifying AS severity. Approximately one-third of patients with normal ejection fraction and severe AS by AVA have nonsevere AS by $\Delta P_{m}$ when measured by preoperative transthoracic echocardiography (TTE). Given the use of positive pressure ventilation and general anesthesia in the pre-cardiopulmonary bypass (pre-CPB) period, we hypothesized that discordance between $\triangle \mathrm{P}_{\mathrm{m}}$ and AVA during pre-CPB transesophageal echocardiography (TEE) would be higher than previously reported by TTE.

METHODS: We retrospectively examined pre-CPB TEE data for patients who had aortic valve replacement, with or without coronary artery bypass grafting, from 2000 to 2012 . Patients were excluded if they had ejection fraction $<55 \%$, emergency surgery, repeat sternotomy, moderate or severe mitral regurgitation, or severe aortic regurgitation. Only patients with both pre-CPB AVA and $\triangle \mathrm{P}_{\mathrm{m}}$ measurements were included. Patients were grouped according to severity (mild, moderate, and severe) by AVA or $\Delta \mathrm{P}_{\mathrm{m}}$. Discordance was defined as disagreement between severities based on either parameter. RESULTS: A total of 277 patients met inclusion criteria. There were 227 patients with AVA $\leq 1.0 \mathrm{~cm}^{2}$. The proportion of these patients with a $\Delta \mathrm{P}_{\mathrm{m}}<40 \mathrm{~mm} \mathrm{Hg}$ was $54 \%$ (95\% confidence interval, $47 \%-61 \%)$. The rate of discordance was significantly higher than the rate $(37 \%$; $P<0.001$ ) found in previously reported analyses using TTE. Of the patients with a $\Delta P_{m} \geq 40 \mathrm{~mm}$ $\mathrm{Hg}$, only $8 \%(n=9 / 113)$ had a discordant AVA. In contrast, of the patients with $\Delta \mathrm{P}_{\mathrm{m}}<40 \mathrm{~mm}$ $\mathrm{Hg}, 80 \%(n=131 / 164)$ had a discordant AVA.

CONCLUSIONS: We confirmed our hypothesis that grading AS by $\triangle \mathrm{P}_{\mathrm{m}}$ and AVA during pre-CPB TEE exhibits higher discordance than reported for TTE by others. It remains unclear whether these discrepancies reflect the effect of general anesthesia, imaging modality (TTE versus TEE) differences, inaccuracies in AS grading cutoffs when applied to pre-CPB TEE, or selection bias of the surgical population. (Anesth Analg 2016;122:953-8)
\end{abstract}

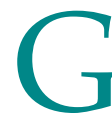
rading aortic valve stenosis (AS) can be challenging because of inconsistencies between the methods used to assign severity. For example, during transthoracic echocardiography (TTE), approximately $22 \%$ to $37 \%$ of patients with normal left ventricular ejection fraction (LVEF) and an aortic valve area (AVA) $\leq 1.0 \mathrm{~cm}^{2}$, which represents severe AS, have a mean gradient $\left(\Delta \mathrm{P}_{\mathrm{m}}\right)<40 \mathrm{~mm}$ $\mathrm{Hg}$, which represents nonsevere AS. ${ }^{1-5}$ Similarly, cardiac

From the *Department of Anesthesiology, †Social Science Research Institute, and $\ddagger$ Department of Biostatistics and Bioinformatics, Duke University, Durham, North Carolina.

George Whitener, MD, is currently affiliated with Department of Anesthesia and Perioperative Medicine, Medical University of South Carolina, Charleston, South Carolina.

Jeff McKenzie, MD, is currently affiliated with Olympia Anesthesia Associates, Olympia, Washington.

Accepted for publication October 4, 2015.

Funding: None.

The authors report no conflicts of interest.

The abstract for this research report was previously presented, in part, at the 2014 Society of Cardiovascular Anesthesiology National Meeting in New Orleans, LA (Abstract was selected for oral presentation).

Reprints will not be available from the authors.

Address correspondence to George Whitener, MD, Department of Anesthesia and Perioperative Medicine, Medical University of South Carolina, 25 Courtenay Dr., Suite 4210, MSC 240, Charleston, SC 29425. Address e-mail to whiteneg@musc.edu.

Copyright (C) 2015 International Anesthesia Research Society DOI: 10.1213/ANE.0000000000001099 catheterization data exhibit a discordance rate of $25 \%$ when grading AS in similar patients. ${ }^{5}$ These inconsistencies have been attributed to stroke volume variability, despite normally appearing left ventricular (LV) function, small LV size, diastolic dysfunction, chronic afterload changes from hypertension, and underestimation of AVA secondary to the erroneous assumption that the left ventricular outflow tract (LVOT) is a circle rather than an ellipse. ${ }^{6-12}$ Inconsistent AS grading is problematic because misinterpretation of grading parameters may delay surgical intervention and negatively affect patients. ${ }^{1-3}$

AS severity is defined by the following echocardiographic parameters: peak velocity, $\Delta \mathrm{P}_{\mathrm{m}}$, AVA by continuity equation, dimensionless index, and indexed AVA (Table 1). ${ }^{13,14}$ The 2014 American Heart Association/ American College of Cardiology guidelines for the management of patients with valvular heart disease present an algorithmic approach for echocardiographic assessment of AS. ${ }^{14}$ In a patient with an abnormally appearing aortic valve, peak velocity or $\Delta \mathrm{P}_{\mathrm{m}}$ is used initially to determine whether the valve meets criteria for aortic valve replacement (AVR). Subsequently, the presence of symptoms, LVEF, and AVA stratify valves appropriate for AVR. ${ }^{14}$ Of note, peak velocity and $\Delta \mathrm{P}_{\mathrm{m}}$ are primary measurements obtained directly by Doppler echocardiography. Meanwhile, the AVA continuity equation calculation depends on accurate measurement of the LVOT diameter, as well as velocity measurements through the LVOT and 


\begin{tabular}{lccc}
\hline Table 1. Aortic Stenosis & Grading Limits & \\
Measurement & Mild & Moderate & Severe \\
Peak velocity $(\mathrm{m} / \mathrm{s})$ & $<3.0$ & $3.0-4.0$ & $>4.0$ \\
Mean gradient $(\mathrm{mm} \mathrm{Hg})$ & $<20$ & $20-40$ & $\geq 40$ \\
Aortic valve area $\left(\mathrm{cm}^{2}\right)$ & $>1.5$ & $1.0-1.5$ & $\leq 1.0$ \\
Indexed valve area $\left(\mathrm{cm}^{2} / \mathrm{m}^{2}\right)$ & $>0.85$ & $0.60-0.85$ & $<0.6$ \\
Dimensionless index & $>0.50$ & $0.25-0.50$ & $<0.25$
\end{tabular}

Adapted from Baumgartner et al. ${ }^{13}$ and Nishimura et al. ${ }^{14}$

aortic valve. For this reason, AVA calculation is prone to error compared with a $\Delta \mathrm{P}_{\mathrm{m}}$ measurement.

Although inconsistencies for grading AS with AVA and $\Delta \mathrm{P}_{\mathrm{m}}$ are well known for preoperative TTE, they are routinely used for grading AS in the pre-cardiopulmonary bypass (pre$\mathrm{CPB})$ context. In this study, we investigate the frequency of discordance between grading AS with $\Delta \mathrm{P}_{\mathrm{m}}$ measurements and AVA calculations during pre-CPB transesophageal echocardiography (TEE) to provide insight into their reliability for pre-CPB assessment of AS severity. Conventional AS severity cutoffs were derived from TTE studies performed in awake, spontaneously breathing patients. ${ }^{14-18}$ However, cardiac anesthesiologists perform pre-CPB TEE in anesthetized patients receiving positive pressure ventilation. Because general anesthesia and positive pressure ventilation may influence cardiac loading conditions, we hypothesized that grading discordance by pre-CРB TEE would be higher than previously reported for TTE by others.

\section{METHODS}

We obtained Duke University IRB approval, which granted waiver of consent to perform a retrospective database study for information collected between January 1, 2000, and December 31,2012 . This study was an investigator-initiated, single-center, retrospective review of the Duke University, Department of Anesthesiology perioperative echocardiography-reporting database. This database includes all adult patients who have undergone cardiac surgery at Duke University Medical Center and had a TEE report generated electronically since January 1, 2000. The Duke Health Information Technologies Solutions (DHTS) Perioperative Development Group (PDG) maintains the reporting system. A cardiothoracic anesthesiology fellow, attending, or both, generated TEE reports as part of a dedicated perioperative echocardiography training program. All imaging and reports were subsequently reviewed offline by an independent cardiothoracic anesthesiologist to confirm the accuracy of the report.

\section{Subject Selection}

We reviewed all patients in the database, who underwent AVR with or without coronary artery bypass grafting from January 1, 2000, until December 31, 2012. Patients were included if the echocardiographer reported both a pre-CPB $\Delta \mathrm{P}_{\mathrm{m}}$ and an AVA. Patients were excluded if they had emergency surgery or repeat sternotomy. Patients were also excluded if they had an ejection fraction $<55 \%$, moderate or severe mitral regurgitation (MR), or severe aortic insufficiency (AI).

\section{Definitions of Variables}

Two variables, $\Delta \mathrm{P}_{\mathrm{m}}$ and AVA, were obtained according to standard practice guidelines established by the American Society of Echocardiography. ${ }^{13}$ The $\Delta \mathrm{P}_{\mathrm{m}}$ was obtained in either the deep transgastric long-axis or the transgastric long-axis view with the continuous wave Doppler beam aligned as parallel as possible to the direction of blood flow. The AVA was calculated by application of the continuity equation:

$$
\operatorname{AVA}\left(\mathrm{cm}^{2}\right)=\frac{\left(0.785\left(\text { LVOT Diameter }^{2}\right) \times\left(\mathrm{VTI}_{\text {LVOT }}\right)\right.}{\left(\mathrm{VTI}_{\text {Aortic Valve }}\right)}
$$

Individual measurement of the LVOT diameter was done in the mid-esophageal long-axis view. LVOT velocity time integral and aortic valve velocity time integral were each measured via pulsed wave Doppler or continuous wave Doppler, respectively, in the deep transgastric long-axis or transgastric long-axis views. All measured parameters were obtained per protocol, which required measurements in temporal succession and during normotension (systolic blood pressure $<140 \mathrm{~mm} \mathrm{Hg}$, $>100 \mathrm{~mm} \mathrm{Hg}$ ), postinduction of anesthesia before sternotomy.

The echocardiographer caring for the patient initially determined LVEF, while a reviewing echocardiographer confirmed this assessment offline. Various modes of assessment were used, including visual inspection, the Simpson method of disks, fractional shortening, or 3D echocardiographic full-volume reconstruction.

\section{Statistical Analysis}

IRB approval was obtained in early 2013; therefore, we collected retrospective data as far as possible, up through December 31, 2012. Pre-CPB TEE $\Delta P_{m}$ and AVA values were extracted for all patients meeting clinical inclusion criteria. These values were grouped according to AS severity (mild, moderate, and severe) and compared for discordance rates based on current grading guidelines for $\Delta \mathrm{P}_{\mathrm{m}}$ and AVA. Values were considered "discordant" if there was disagreement between severities based on either parameter. The discordant proportions of $\Delta \mathrm{P}_{\mathrm{m}}$ and AVA by AS severity were calculated by dividing the number of cases in each cell of a 2-way table by the marginal total of each severity category. Confidence intervals of $95 \%$ for each discordance rate were computed using Newcombe-Wilson tests with continuity correction. ${ }^{19,20}$ All statistical analyses were performed using SAS version 9.3 (SAS Institute, Inc., Cary, NC). To specifically test our hypothesis, the discordance rate of lowgradient, severe AS (AVA $\leq 1.0, \Delta \mathrm{P}_{\mathrm{m}}<40$ ) was compared with the discordance rate found for a similar population via TTE (37\%) by Minners et al. ${ }^{5}$ using the Fisher exact test.

In addition, AVA (y-axis) data points were plotted against $\Delta \mathrm{P}_{\mathrm{m}}$ (x-axis) and a curve (Fig. 1) was fit to the data based on the relationship:

$$
\mathrm{AVA}=\frac{\mathrm{C}}{\sqrt{\Delta \mathrm{P}_{\mathrm{m}}}}
$$

This relationship, as well as the derivation of the coefficient, C, has been described in detail elsewhere. ${ }^{5}$ We used nonlinear regression analysis (SAS Proc MODEL, SAS 9.4) to estimate $\mathrm{C}$, accompanied by its standard error value. The distribution of residuals was approximately normal without correlation between the residuals and another predictor. 


\section{RESULTS}

After applying all patient selection criteria, 277 patients had both AVA and $\Delta \mathrm{P}_{\mathrm{m}}$ available for analysis (Fig. 2). The demographic data for the study population of 277 patients are summarized in Table 2. In this population, 227 patients had an AVA $\leq 1.0 \mathrm{~cm}^{2}$. Of these patients, $54 \%$ (95\% confidence interval [CI], 47\%-61\%) had a discordant $\Delta \mathrm{P}_{\mathrm{m}}$ (Table 3), which is significantly higher than the discordance rate for AVA $\leq 1.0 \mathrm{~cm}^{2}$ reported by Minners et al..$^{5}(37 \% ; P<0.001)$ for TTE.

When $\Delta \mathrm{P}_{\mathrm{m}}$ was $\geq 40 \mathrm{~mm} \mathrm{Hg}$, only $8 \%(95 \% \mathrm{CI}, 4 \%-15 \%)$ of patients had a discordant AVA (AVA $\left.>1.0 \mathrm{~cm}^{2}\right)$. In contrast, when $\Delta \mathrm{P}_{\mathrm{m}}$ was between 20 and $40 \mathrm{~mm} \mathrm{Hg}(n=145)$ and consistent with moderate AS, $84 \%$ (95\% CI, 77\%-89\%) of patients had an AVA consistent with either severe $(n=$ $119)$ or mild $(n=3)$ AS. When $\Delta \mathrm{P}_{\mathrm{m}}$ was $<40 \mathrm{~mm} \mathrm{Hg}$, the discordance rate was $80 \%(n=131 / 164$; Table 3$)$. We found an overall discordance rate of $140 / 277,51 \%$ (95\% CI, $45 \%-$ $57 \%$ ) in the study population. This rate reflects grouping of all grades (mild, moderate, or severe) of AS by either $\Delta \mathrm{P}_{\mathrm{m}}$ or AVA. There were expectedly small numbers of patients categorized as mild AS by $\Delta \mathrm{P}_{\mathrm{m}}(n=19)$ or AVA $(n=14)$ because the study incorporated only patients receiving valve replacement.

AVA was plotted against $\Delta \mathrm{P}_{\mathrm{m}}$ and a modeling curve was fit $\left(R^{2}=0.42\right)$ to the data as described in the Methods (Fig. 1). The result for coefficient, $C$, for modeling the data via the relationship, AVA $=C / \sqrt{\left(\Delta \mathrm{P}_{\mathrm{m}}\right)}$, was 4.83 (SE, 0.096). Lines of demarcation for currently accepted cutoffs for severe AS were superimposed over the data.

\section{DISCUSSION}

We confirmed our hypothesis that discordance between $\Delta \mathrm{P}_{\mathrm{m}}$ and AVA was higher during pre-CPB TEE compared

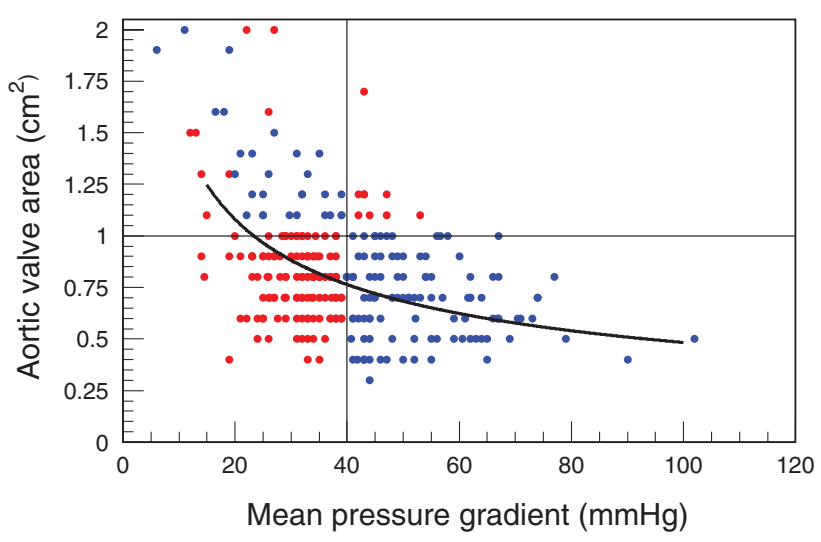

Figure 1. Aortic valve area (AVA) versus mean gradient $\left(\Delta P_{m}\right)$ during pre-cardiopulmonary bypass transesophageal echocardiography. A scatter plot of aortic valve stenosis (AS) grading parameters, AVA versus $\Delta \mathrm{P}_{\mathrm{m}}$, for study subjects. Red data points represent discordant data, disagreement of AS severity based on either parameter according to current guideline cutoffs for all grades of AS. ${ }^{13,14}$ Blue data points represent concordant data. A nonlinear regression curve (modeled by the equation, $\mathrm{AVA}=4.83 / \sqrt{\left(\Delta \mathrm{P}_{\mathrm{m}}\right)}$ is shown fit $(R=0.42)$ to the data. The plot is divided into quadrants at the demarcation of severe AVA $\leq 1.0 \mathrm{~cm}^{2}$ and $\Delta P_{m} \geq 40 \mathrm{~mm} \mathrm{Hg}$. Cutoff lines highlight areas of high concordance and discordance. Using an AVA $=1.0 \mathrm{~cm}^{2}$ in our model gives a $\Delta \mathrm{P}_{\mathrm{m}}$ of $23.3 \mathrm{~mm} \mathrm{Hg}$, whereas using $\Delta P_{m}=40 \mathrm{~mm} \mathrm{Hg}$ provides an AVA of $0.76 \mathrm{~cm}^{2}$. Note that at high $\Delta P_{m} \mathrm{~s}$ $\left(\Delta \mathrm{P}_{\mathrm{m}} \geq 40 \mathrm{~mm} \mathrm{Hg}\right)$, there is excellent concordance with AVA and at lower $\Delta \mathrm{P}_{\mathrm{m}} \mathrm{s}\left(\Delta \mathrm{P}_{\mathrm{m}}<40 \mathrm{~mm} \mathrm{Hg}\right)$, there is substantial discordance. with preoperative TTE, as reported in the literature. We obtained a discordance rate of $54 \%$ for patients when AVA $\leq 1.0 \mathrm{~cm}^{2}$ and an overall discordance rate across all grades of AS of $51 \%$. When $\Delta \mathrm{P}_{\mathrm{m}}$ was $<40 \mathrm{~mm} \mathrm{Hg}, 80 \%$ of patients exhibited a discordant AVA. Conversely, when $\Delta \mathrm{P}_{\mathrm{m}}$ was $\geq 40 \mathrm{~mm} \mathrm{Hg}$, only $8 \%$ of patients exhibited a discordant AVA (Table 3). Modeling our data illustrates how pre-CPB values of $\Delta \mathrm{P}_{\mathrm{m}}$ and AVA diverge from guideline grading cutoffs (Fig. 1).

Substantially increased discordance when $\Delta \mathrm{P}_{\mathrm{m}}$ $<40 \mathrm{~mm} \mathrm{Hg}$ during pre-CPB TEE suggests that either pre-CPB TEE $\Delta \mathrm{P}_{\mathrm{m}}$ is, on average, lower relative to preoperative TTE $\Delta \mathrm{P}_{\mathrm{m}}$, or pre-CPB TEE AVA calculations are, on average, lower relative to preoperative TTE AVA calculations or both. General anesthesia is a potential culprit for such alterations in $\Delta \mathrm{P}_{\mathrm{m}}$ and AVA. For example, grading discrepancies between pre-CPB TEE and preoperative TTE MR grading have been well established; pre-CPB TEE underestimates MR severity, probably because of changes in loading conditions. ${ }^{21-24}$ Likewise, decreased loading may lead to underestimation of $\Delta \mathrm{P}_{\mathrm{m}}$ across the aortic valve while under general anesthesia. This consequence has practical importance because artificially low-gradient measurements despite normal LVEF could lead to confusion and underestimation of disease. This problem would be especially challenging in the case of incidental AS. Patients who classify as mild AS $\left(\Delta \mathrm{P}_{\mathrm{m}}<20\right)$ by pre-CPB might classify as moderate $A S\left(\Delta P_{m} \geq 20\right)$, if they were undergoing TTE without general endotracheal anesthesia. Moderate AS in the setting of additional cardiac surgery is an indication for AVR. ${ }^{14}$

Loading conditions affect AVA calculations as well. In patients with AS, AVA by the continuity equation is inversely related to blood pressure because of changes in transvalvular flow. ${ }^{25}$ Thus, without controlling for the effects of general anesthesia, one would expect pre-CPB TEE AVA calculations to yield different values than preoperative TTE AVA calculations in the same patients. Although factors such as LVOT diameter underestimation and beat-to-beat variability in blood flow make AVA calculations prone to error, these problems affect both preoperative TTE and preCPB TEE and do not explain increased discordance during pre-CPB TEE. ${ }^{26,27}$ A comparison between preoperative TTE and pre-CPB TEE for both AVA and $\Delta P_{m}$ values is warranted to see which parameter drives discordance during pre-CPB TEE. Similarly, the impact of general anesthesia on AVA calculations and $\Delta \mathrm{P}_{\mathrm{m}}$ measurements during pre-CPB TEE requires further investigation.

\section{Limitations}

The strength of our study lies in our quality-assured echocardiography database, including a large patient population over a 12-year period in a high-volume cardiothoracic surgery center. However, the study is limited by its retrospective design and inability to control for cardiac output, transvalvular flow, LV size, blood pressure, heart rate, and arterial compliance. Such data points were not tied to the echocardiographic data and would be impractical to obtain retrospectively. Nevertheless, the sample size is relatively large, which should distribute this unpredictability 


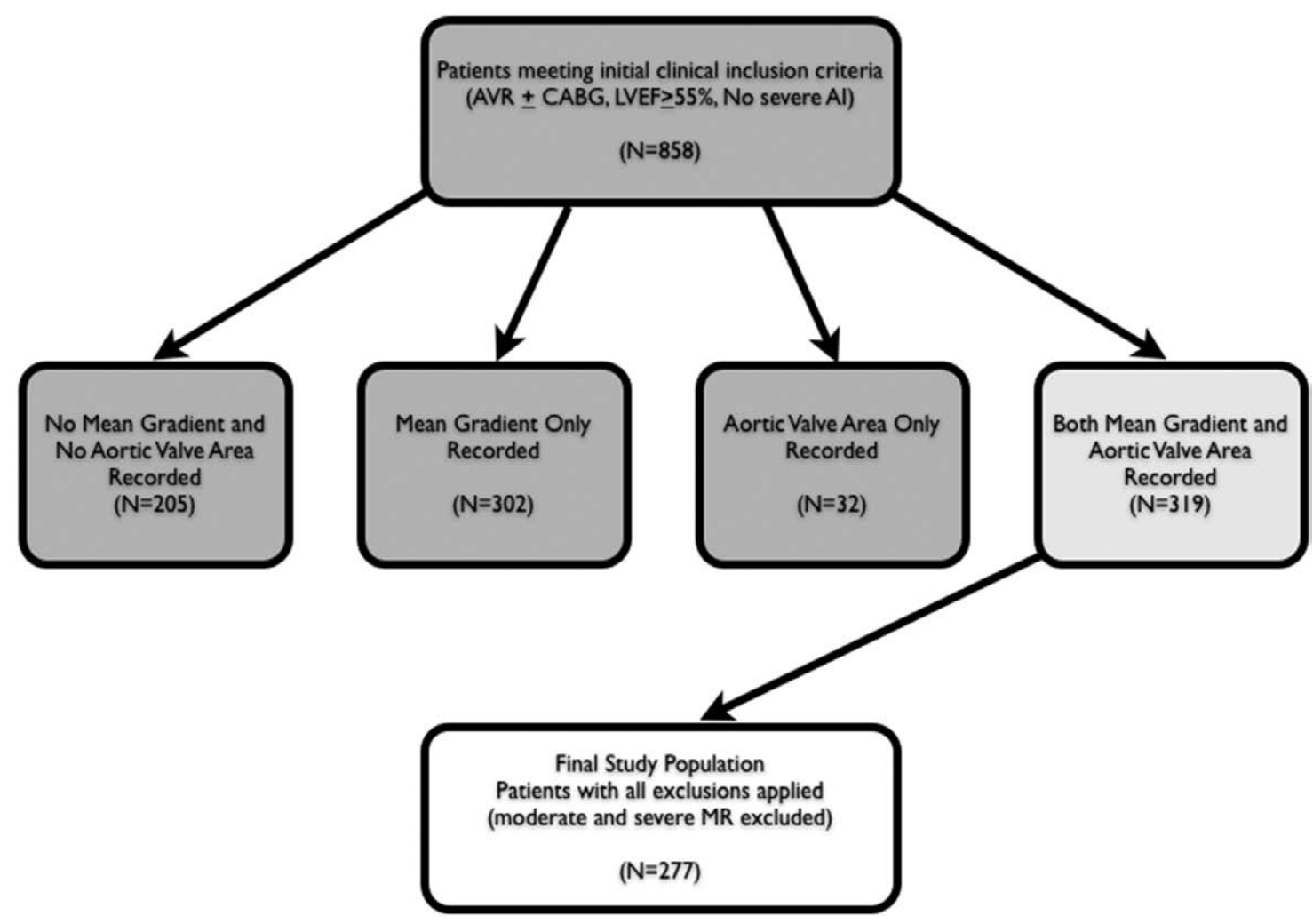

Figure 2. Patient study population. Flow diagram showing breakdown of patients meeting inclusion criteria, as well as availability of mean gradient and aortic valve area values. AI = aortic insufficiency; AVR = aortic valve replacement; CABG = coronary artery bypass grafting; $\mathrm{LVEF}=$ left ventricular ejection fraction; MR = mitral regurgitation .

\begin{tabular}{lc} 
Table 2. Patient Demographics & \\
Characteristic & $\boldsymbol{n}=\mathbf{2 7 7}$ \\
Age at surgery, $\mathrm{y}^{a}$ & $69.1 \pm 11$ \\
Male sex, $n(\%)^{b}$ & $151(54.5)$ \\
Body mass index, $\mathrm{kg} / \mathrm{m}^{2 a, c}$ & $30.2 \pm 6$ \\
Surgical procedure, $n(\%)^{b}$ & \\
$\quad$ AVR & $177(63.9)$ \\
$\quad$ CABG + AVR & $100(36.1)$ \\
Aortic insufficiency, $n(\%)^{b}$ & \\
$\quad$ None/trace & $109(39.3)$ \\
$\quad$ Mild & $90(32.5)$ \\
Moderate & $78(28.2)$ \\
Mitral insufficiency, $n(\%)^{b}$ & \\
$\quad$ None/trace & $240(86.6)$ \\
Mild & $37(13.4)$ \\
\hline
\end{tabular}

$\mathrm{AVR}=$ aortic valve replacement; $\mathrm{CABG}=$ coronary artery bypass grafting. aData presented as mean $\pm \mathrm{SD}$.

${ }^{b}$ Data presented as frequency in the population.

${ }^{c} n=256$ for body mass index because of missing data.

randomly across both discordant and concordant patients, thus limiting a systematic error.

In addition, we did not retrieve the reference method for the preoperative AS grade determination. Similarly, we did not include data on the qualitative appearance of the valves. It is unclear whether this information may have affected $\Delta \mathrm{P}_{\mathrm{m}}, \mathrm{AVA}$, or discordance between the two.

Two notable parts of our methods differ from guideline cutoffs and the preoperative TTE study used for comparison. First, the cutoff for LVEF in the AS grading guideline algorithm is $50 \%{ }^{14}$ However, we used $55 \%$ as an LVEF cutoff because our database was constructed with cutoffs in $10 \%$ intervals beginning at $<15 \%$ and ending at $>55 \%$. Because individual values were not reported, a group of patients with an LVEF $>50 \%$ would not have been retrievable. Because we used a stricter estimate of "normal" LVEF ( $>55 \%$ vs $50 \%$ ), this difference by itself would unlikely select for patients with lower $\Delta \mathrm{P}_{\mathrm{m}}$ and higher rates of discordance. Second, moderate AI was not excluded in our study. Moderate AI, however, would increase $\Delta \mathrm{P}_{\mathrm{m}}$; therefore, including such patients might underestimate the rate of discordance in pre-CPB TEE.

Finally, the method for determining left ventricular systolic function was not standardized for each study patient. Some of the examinations likely had patients labeled as normal systolic function by visual inspection alone, which leaves the assessments open to the judgment of the reviewing echocardiographer. Further prospective work is necessary to better control for such potential confounders.

\section{CONCLUSIONS}

Our study questions the reliability of applying current TTEderived AS grading cutoffs to pre-CPB TEE $\triangle \mathrm{P}_{\mathrm{m}}$ measurements and AVA calculations. Given these problems, cardiac anesthesiologists must not overlook qualitative 2D assessment and other parameters for grading AS. Until there is a reliable, validated method for correlating preoperative TTE with pre-CPB TEE values, alternate grading methods that account for differences in loading conditions and LV size should be considered. Further work is necessary to accurately interpret pre-CPB grading values when applying TTE 


\begin{tabular}{|c|c|c|c|c|c|c|}
\hline \multirow[b]{2}{*}{$\begin{array}{l}\text { AS by mean gradient } \\
\text { ( } \triangle \mathrm{Pm} ; \mathrm{mm} \mathrm{Hg})\end{array}$} & \multicolumn{3}{|c|}{ Aortic stenosis by aortic valve area (AVA; $\mathbf{c m}^{2}$ ) } & \multirow[b]{2}{*}{ All } & \multirow[b]{2}{*}{$\begin{array}{l}\text { Discordance } \\
\text { rate }(\%)\end{array}$} & \multirow[b]{2}{*}{$95 \% \mathrm{Cl}$} \\
\hline & $>1.5$ (mild) & $\begin{array}{c}1<\text { AVA }<1.5 \\
\text { (moderate) }\end{array}$ & $<1.0$ (severe) & & & \\
\hline$<20$ (mild) & 10 & 5 & 4 & 19 & $9 / 19(47 \%)$ & $25 \%-70 \%$ \\
\hline $20 \leq \Delta \mathrm{Pm}<40$ (moderate) & 3 & 23 & 119 & 145 & $122 / 145(84 \%)$ & $77 \%-89 \%$ \\
\hline$\geq 40$ (severe) & 1 & 8 & 104 & 113 & $9 / 113(8 \%)$ & $4 \%-15 \%$ \\
\hline All & 14 & 36 & 227 & 277 & & \\
\hline Discordance rate $(\%)$ & $4 / 14(29 \%)$ & $13 / 36(36 \%)$ & $123 / 227(54 \%)$ & & $140 / 277(51 \%)$ & \\
\hline 95\% Confidence Interval & $10 \%-58 \%$ & $21 \%-54 \%$ & $47 \%-61 \% *$ & & & $45 \%-57 \%$ \\
\hline
\end{tabular}

$\mathrm{AS}=$ aortic stenosis; $\mathrm{AVA}=$ aortic valve area; $\mathrm{Cl}=$ confidence interval; $\Delta \mathrm{P}_{\mathrm{m}}=$ mean gradient.

Bold data show discordance rate in pre-cardiopulmonary bypass TEE for patients with AVA $<1.0 \mathrm{~cm}^{2}$. Italicized data highlights numbers of discordant patients in each severity category.

${ }^{*} P<0.001$; $P$ value reflects comparison of study patients with the discordance rate for AVA $\leq 1.0 \mathrm{~cm}^{2}$ reported for preoperative transthoracic echocardiography by Minners et al. ${ }^{5}$

grading cutoffs and to determine whether pre-CPB TEE deserves a separate, standardized AS grading schema. $\#$

\section{DISCLOSURES}

Name: George Whitener, MD.

Contribution: This author helped design the study, conduct the study, analyze the data, and write the manuscript.

Attestation: George Whitener has seen the original study data, reviewed the analysis of the data, approved the final manuscript, and is the author responsible for archiving the study files.

Name: Jeff McKenzie, MD.

Contribution: This author helped design the study, conduct the study, and write the manuscript.

Attestation: Jeff McKenzie has seen the original study data, reviewed the analysis of the data, and approved the final manuscript.

Name: Igor Akushevich, PhD.

Contribution: This author helped analyze the data and write the manuscript.

Attestation: Igor Akushevich has seen the original study data, reviewed the analysis of the data, and approved the final manuscript.

Name: William D. White, MPH.

Contribution: This author helped conduct the study and analyze the data.

Attestation: William D. White has seen the original study data, reviewed the analysis of the data, and approved the final manuscript.

Name: Ishwori B. Dhakal, MS.

Contribution: This author helped analyze the data.

Attestation: Ishwori B. Dhakal has seen the original study data, reviewed the analysis of the data, and approved the final manuscript.

Name: Alina Nicoara, MD, FASE.

Contribution: This author helped conduct the study and write the manuscript.

Attestation: Alina Nicoara has seen the original study data, reviewed the analysis of the data, and approved the final manuscript.

Name: Madhav Swaminathan, MD, FASE, FAHA.

Contribution: This author helped design the study and write the manuscript.

Attestation: Madhav Swaminathan has seen the original study data, reviewed the analysis of the data, and approved the final manuscript.

This manuscript was handled by: Martin J. London, MD.

\section{REFERENCES}

1. Hachicha Z, Dumesnil JG, Bogaty P, Pibarot P. Paradoxical lowflow, low-gradient severe aortic stenosis despite preserved ejection fraction is associated with higher afterload and reduced survival. Circulation 2007;115:2856-64

2. Barasch E, Fan D, Chukwu EO, Han J, Passick M, Petillo F, Norales A, Reichek N. Severe isolated aortic stenosis with normal left ventricular systolic function and low transvalvular gradients: pathophysiologic and prognostic insights. J Heart Valve Dis 2008;17:81-8

3. Dumesnil JG, Pibarot P, Carabello B. Paradoxical low flow and/or low gradient severe aortic stenosis despite preserved left ventricular ejection fraction: implications for diagnosis and treatment. Eur Heart J 2010;31:281-9

4. Jander N, Minners J, Holme I, Gerdts E, Boman K, Brudi P, Chambers JB, Egstrup K, Kesäniemi YA, Malbecq W, Nienaber CA, Ray S, Rossebø A, Pedersen TR, Skjærpe T, Willenheimer R, Wachtell K, Neumann FJ, Gohlke-Bärwolf C. Outcome of patients with low-gradient "severe" aortic stenosis and preserved ejection fraction. Circulation 2011;123:887-95

5. Minners J, Allgeier M, Gohlke-Baerwolf C, Kienzle RP, Neumann FJ, Jander N. Inconsistent grading of aortic valve stenosis by current guidelines: haemodynamic studies in patients with apparently normal left ventricular function. Heart 2010;96:1463-8

6. Dumesnil JG, Shoucri RM. Effect of the geometry of the left ventricle on the calculation of ejection fraction. Circulation 1982;65:91-8

7. Poulsen SH, Søgaard P, Nielsen-Kudsk JE, Egeblad H. Recovery of left ventricular systolic longitudinal strain after valve replacement in aortic stenosis and relation to natriuretic peptides. J Am Soc Echocardiogr 2007;20:877-84

8. Strotmann JM, Lengenfelder B, Blondelot J, Voelker W, Herrmann S, Ertl G, Weidemann F. Functional differences of left ventricular hypertrophy induced by either arterial hypertension or aortic valve stenosis. Am J Cardiol 2008;101:1493-7

9. Lauten J, Rost C, Breithardt OA, Seligmann C, Klinghammer L, Daniel WG, Flachskampf FA. Invasive hemodynamic characteristics of low gradient severe aortic stenosis despite preserved ejection fraction. J Am Coll Cardiol 2013;61:1799-808

10. Doddamani S, Bello R, Friedman MA, Banerjee A, Bowers JH Jr, Kim B, Vennalaganti PR, Ostfeld RJ, Gordon GM, Malhotra D, Spevack DM. Demonstration of left ventricular outflow tract eccentricity by real time 3D echocardiography: implications for the determination of aortic valve area. Echocardiography 2007;24:860-6

11. Doddamani S, Grushko MJ, Makaryus AN, Jain VR, Bello R, Friedman MA, Ostfeld RJ, Malhotra D, Boxt LM, Haramati L, Spevack DM. Demonstration of left ventricular outflow tract eccentricity by 64-slice multi-detector CT. Int J Cardiovasc Imaging 2009;25:175-81

12. Gaspar T, Adawi S, Sachner R, Asmer I, Ganaeem M, Rubinshtein R, Shiran A. Three-dimensional imaging of the left ventricular outflow tract: impact on aortic valve area estimation by the continuity equation. J Am Soc Echocardiogr 2012;25:749-57 
13. Baumgartner H, Hung J, Bermejo J, Chambers JB, Evangelista A, Griffin BP, Iung B, Otto CM, Pellikka PA, Quinones M, American Society of E, European Association of E. Echocardiographic assessment of valve stenosis: EAE/ASE recommendations for clinical practice. J Am Soc Echocardiogr 2009;22:1-23

14. Nishimura RA, Otto CM, Bonow RO, Carabello BA, Erwin JP $3^{\text {rd }}$, Guyton RA, O'Gara PT, Ruiz CE, Skubas NJ, Sorajja P, Sundt $\mathrm{TM} 3^{\text {rd }}$, Thomas JD; American College of Cardiology/American Heart Association Task Force on Practice Guidelines. 2014 AHA/ ACC guideline for the management of patients with valvular heart disease: executive summary: a report of the American College of Cardiology/American Heart Association Task Force on Practice Guidelines. J Am Coll Cardiol 2014;63:2438-88

15. Otto CM, Pearlman AS, Comess KA, Reamer RP, Janko CL, Huntsman LL. Determination of the stenotic aortic valve area in adults using Doppler echocardiography. J Am Coll Cardiol 1986;7:509-17

16. Otto CM, Pearlman AS. Doppler echocardiography in adults with symptomatic aortic stenosis. Diagnostic utility and costeffectiveness. Arch Intern Med 1988;148:2553-60

17. Otto CM, Pearlman AS, Gardner CL. Hemodynamic progression of aortic stenosis in adults assessed by Doppler echocardiography. J Am Coll Cardiol 1989;13:545-50

18. Kelly TA, Rothbart RM, Cooper CM, Kaiser DL, Smucker ML, Gibson RS. Comparison of outcome of asymptomatic to symptomatic patients older than 20 years of age with valvular aortic stenosis. Am J Cardiol 1988;61:123-30

19. Newcombe RG. Two-sided confidence intervals for the single proportion: comparison of seven methods. Stat Med $1998 ; 17: 857-72$
20. Wilson EB. Probable inference, the law of succession, and statistical inference. J Am Stat Assoc 1927;22:209-12

21. Shiran A, Merdler A, Ismir E, Ammar R, Zlotnick AY, Aravot D, Lazarovici H, Zisman E, Pizov R, Lewis BS. Intraoperative transesophageal echocardiography using a quantitative dynamic loading test for the evaluation of ischemic mitral regurgitation. J Am Soc Echocardiogr 2007;20:690-7

22. Aklog L, Filsoufi F, Flores KQ, Chen RH, Cohn LH, Nathan NS, Byrne JG, Adams DH. Does coronary artery bypass grafting alone correct moderate ischemic mitral regurgitation? Circulation 2001;104:I68-75

23. Grewal KS, Malkowski MJ, Piracha AR, Astbury JC, Kramer CM, Dianzumba S, Reichek N. Effect of general anesthesia on the severity of mitral regurgitation by transesophageal echocardiography. Am J Cardiol 2000;85:199-203

24. Bach DS, Deeb GM, Bolling SF. Accuracy of intraoperative transesophageal echocardiography for estimating the severity of functional mitral regurgitation. Am J Cardiol 1995;76:508-12

25. Little SH, Chan KL, Burwash IG. Impact of blood pressure on the Doppler echocardiographic assessment of severity of aortic stenosis. Heart 2007;93:848-55

26. Piazza N, de Jaegere P, Schultz C, Becker AE, Serruys PW, Anderson RH. Anatomy of the aortic valvar complex and its implications for transcatheter implantation of the aortic valve. Circ Cardiovasc Interv 2008;1:74-81

27. Maslow AD, Mashikian J, Haering JM, Heindel S, Douglas P, Levine R. Transesophageal echocardiographic evaluation of native aortic valve area: utility of the double-envelope technique. J Cardiothorac Vasc Anesth 2001;15:293-9 